LEADING ARTICLE

\title{
Effects of growth factors and receptor blockade on gastrointestinal cancer
}

\section{R J Playford, H Wassan, S Ghosh}

Gut 2004;53:1059-1063. doi: 10.1136/gut.2003.038620

The advent of recombinant peptide technology offers the potential to use one or several peptides to treat a variety of gastrointestinal conditions. However, although cell culture and animal models have shown proof of concept, we are still at a relatively early stage in translating their use to standard clinical practice. Similarly, peptide and nonpeptide antagonists of growth factor receptors show great potential as novel antichemotherapy agents. However, their actual place in clinical practice has yet to be established.

See end of article for authors' affiliations

Correspondence to: Professor R J Playford, Gastroenterology Section, Division of Medicine, Imperial College London, Hammersmith Hospital, Ducane Rd, London W12 ONN, UK:

r.playford@imperial.ac.uk

Received 17 March 2004 Accepted for publication 20 March 2004

\section{COMPLEXITY AND MULTIPLE ACTIONS OF RECEPTOR SIGNALLING}

One of the major issues relating to the use of growth factor agonists and antagonists is that because of the complexity of receptor activation and signalling and the multiple pathophysiological functions that operate through these systems, there may be a higher than usual risk of unexpected adverse events. As an example, the signalling pathways and actions of epidermal growth factor receptor (EGFR) activation are briefly described.

EGFR is a typical transmembrane tyrosine extracellular ligand binding region, a membrane spanning segment that anchors the receptor to the cell membrane, and an intracellular segment that possesses tyrosine kinase activity. ${ }^{1}$ Ligand binding results in receptor dimerisation and activation of the tyrosine kinase enzyme within the intracellular domain of the receptor. ${ }^{2}$ This tyrosine kinase activation initiates signalling cascades via PI3-K, Akt, and STAT, or via the Ras/Raf MAPK pathways which, acting via several mechanisms including altered gene expression, ultimately results in increased proliferation, resistance to radio- or chemotherapy, increased cell survival via an antiapoptotic mechanism, as well as influencing crypt fission and angiogenesis. ${ }^{3}$ In addition, EGFR activation can also affect acid and bicarbonate secretion, sodium and glucose uptake, mucus production, smooth muscle contractility, and increased cytoprotection by poorly identified mechanisms. Furthermore, the realisation that heterodimerisation of the EGFR with other members of the erb receptor family can occur adds to the complexity of the situation and is an area which is relatively poorly understood.

\section{GROWTH FACTOR AGONISTS}

What diseases may peptide agonists (or nonpeptide analogues) be useful for? The high efficacy of acid suppressants and Helicobacter pylori eradication regimens probably limit the value of such approaches for oesophagitis and peptic ulceration, except in the most intractable of cases. There are however a number of serious gastrointestinal pathologies where novel therapies might prove useful, including their use for multiorgan failure, ${ }^{4}$ necrotising enterocolitis, and liver protection and regeneration. ${ }^{6}$ Three conditions worthy of particular focus are short bowel syndrome, chemotherapy induced mucositis, and inflammatory bowel disease. These are discussed further below. kinase signalling receptor. It consists of an

\begin{abstract}
"Systemic administration of individual growth factors, such as EGF and glucagonlike peptide 2 (GLP-2), may provide an important alternative acting via stimulation of bowel growth"
\end{abstract}

Peptide therapy for short bowel syndrome is already in common usage as octreotide

Abbreviations: EGF, epidermal growth factor; EGFR, epidermal growth factor receptor; GLP-2, glucagon-like peptide 2; TGF- $\beta$, transforming growth factor $\beta ; \mathrm{GnRH}$, gonadotrophin releasing hormone; TKI, tyrosine kinase inhibitor 
(somatostatin analogue without significant growth factor effects) already has a place in reducing ileostomy output. However, when metabolic balance cannot be maintained, present therapeutic options consist of long term parenteral (intravenous) feeding or, in a few selected cases, small bowel transplantation. Unfortunately, both of these options are associated with high cost and morbidity. Systemic administration of individual growth factors, such as EGF and glucagon-like peptide 2 (GLP-2), may provide an important alternative acting via stimulation of bowel growth. Evidence in favour of this approach includes the findings that systemic administration of EGF stimulated bowel growth in rats receiving total parenteral nutrition ${ }^{7}$ and oral EGF helped restore glucose transport and phlorizin binding in rabbit intestines following jejunal resection. ${ }^{8}$ Similarly, GLP-2 has been shown to improve intestinal adaptation and nutrient absorption after major small bowel resection in rats. ${ }^{9}$ A recent study has demonstrated that GLP-2 also acts as a tropic factor in humans with short bowel syndrome, causing a significant trophic effect on the intestine by stimulating enterocyte proliferation while at the same time reducing rates of enterocyte apoptosis. Significantly greater intestinal absorption of energy, water, and nitrogen was also seen. ${ }^{10}$ Further larger trials are ongoing.

In recent years, high dose chemotherapy protocols are being increasingly used in an attempt to improve cancer cure rates. As a result of this escalation in dosing, toxic side effects on the bone marrow or gastrointestinal tract can be the factor limiting the dose or duration of treatment. The breakdown in mucosal integrity may range from oral stomatitis to massive intestinal ulceration. Strategies to protect these tissues and encourage their recovery may therefore facilitate the use of higher dosage with greater potential for cure. Several peptide growth factors, such as EGF and transforming growth factor $\beta$ (TGF- $\beta$ ), are currently under examination. Examples include the findings that EGF enhances repair of rat intestinal mucosa damaged by methotrexate, ${ }^{11}$ TGF- $\beta$ ameliorates chemotherapy induced mucositis, ${ }^{12}$ and administration of a cheese whey derived preparation reduced methotrexate induced gut injury in mice. ${ }^{13}$ Although these preliminary studies have often shown great initial promise, it is important to realise that equivalent benefit has yet to be confirmed in clinical trials. For example, in a phase I clinical study of patients undergoing chemotherapy, EGF had only a minor beneficial effect in reducing mouth ulceration. ${ }^{14}$

\section{"If peptides with growth stimulatory or inhibitory effects are to be used, timing of administration is likely to be critical" $^{\prime \prime}$}

If peptides with growth stimulatory or inhibitory effects are to be used, timing of administration is likely to be critical; growth arresting factors might protect bone marrow or gut from the damaging effects of chemotherapy (which tends to affect areas with the highest cell turnover) if given prior to chemotherapy. In contrast, growth stimulating factors might "rescue" recovery of injured areas if they are administered following chemotherapy. This latter approach is already being used clinically as colony stimulating growth factor is used to stimulate bone marrow recovery following chemotherapy.

The aetiology of ulcerative colitis and Crohn's disease is unknown, and current treatment of these severe incapacitating conditions therefore has to be on an empiric basis. Several peptide growth factors are at various stages of investigation. These include EGF, platelet derived growth factor, TGF- $\beta$, insulin-like growth factor I, keratinocyte growth factor, trefoil peptides, and combination therapy of multiple peptides in the form of bovine colostrum. ${ }^{15}$ Recently, both colostrum and EGF topical therapy has been shown to be beneficial in small pilot studies ${ }^{16}{ }^{17}$ whereas a more disappointing result was seen with systemic keratinocyte growth factor. ${ }^{18}$

\section{GROWTH FACTOR ANTAGONISTS}

There are two sides to every equation, and peptide growth factors are no exception. At the same time as peptide agonists are gaining clinical prominence, peptide and non-peptide growth factor antagonists are showing promise as chemotherapeutic agents for many different forms of malignancy, including gynaecological, respiratory, and gastroenterological tumours.

\section{"Peptide and non-peptide growth factor antagonists are showing promise as chemotherapeutic agents for many different forms of malignancy"}

A phase II clinical trial with the gonadotrophin releasing hormone (GnRH) antagonist cetrorelix in patients with ovarian or mullerian carcinoma who were refractory to platinum chemotherapy showed highly promising results when tested in a limited number of patients. ${ }^{19}$ In addition, cytotoxic GnRH analogues have been developed where, for example, doxorubicin has been covalently coupled to these GnRH analogues. ${ }^{20}$

Based on extensive biological studies, it has become evident that growth factors, their receptors, and/or their related signal transduction pathways, are aberrant in many, if not most, gastrointestinal cancers. The form by which cellular activation takes place varies between tumours and can result from mutation of the receptor itself causing constitutive activation of the receptor, overexpression of the number of normal receptors by the tumour, or by decreased inactivation of the phosphorylated receptor.

The initial rationale for targeting the EGFR in the clinical cancer setting stems from expression studies that showed that EGFR was highly expressed (and frequently coexpressed with TGF- $\alpha$ ) in a large proportion of common cancers and was associated with invasion, metastasis, late stage disease, and poor outcome. ${ }^{21} 22$ Gastrointestinal tract cancers, including colorectal, pancreatic, oesophageal, and head and neck cancers, have been reported to show some of the highest levels of EGFR overexpression when analysed using standard immunohistochemistry (although there is always the concern of methodological problems when just using this approach).

Current EGFR targeted therapies fall into several groups. One group of compounds of EGFR inhibitors that have been developed are known as small molecule tyrosine kinase inhibitors (TKIs). TKIs inhibit the internal catalytic domain TK activity of the EGFR, thus effectively preventing receptor autophosphorylation and subsequent signalling cascades. Clinically, there are at least seven EGFR TKI in phase II and III trials, one of which (Iressa, ZD1839) is licensed for monotherapy in refractory lung cancer. ${ }^{23}$ Some of these drugs also inhibit the erB-2 (HER2) pathway, and one of these, a quinazoline compound (CI-1033), is an irreversible oral panEGFR inhibitor (that is, blocks activity downstream of four of the closely related EGFR/HER family). Although some of these compounds are showing promise for breast cancer therapy, no small molecule EGFR TKI has yet fulfilled its clinical promise with regard to gastrointestinal cancers (although several trial results are awaited).

\footnotetext{
"A further group of compounds that are under active investigation are the EGFR (HER1) monoclonal blocking antibodies"
} 
A further group of compounds that are under active investigation are the EGFR (HERl) monoclonal blocking antibodies. At least four anti-EGFRl monoclonal antibodies are in late stage clinical development, culminating in Cetuximab recently being awarded its therapeutic licence in the treatment of chemotherapy refractory (specifically Irinotecan refractory) metastatic colorectal cancer. Cetuximab (Erbitux) is a chimeric $\operatorname{IgG}_{1}$ high affinity monoclonal antibody directed against the extracellular domain of the human EGFR (HERl). This product has been shown in preclinical studies to enhance antitumour activity when used in combination with chemotherapy and radiation therapy. Cetuximab is known to stimulate receptor internalisation and also prevent binding of TGF- $\alpha$ to the EGFR. Two phase II studies, ${ }^{24}$ one of which was randomised (BOND study), have demonstrated significant efficacy with improvements in progression free survival in metastatic colorectal cancer when used in combination with Irinotecan chemotherapy. More impressively, in patients refractory to Irinotecan, 20\% could be converted to significant responses with resensitisation to Irinotecan with the sequential addition of Cetuximab. Monotherapy with Cetuximab also had efficacy in this study. However, somewhat surprisingly, there was no correlation of response rates with levels of EGFR overexpression in the tumours in either study. In contrast, but somewhat ironically, there does appear to be a strong positive correlation of efficacy with skin toxicity and this general pattern of skin toxicity is emerging as a trend for the use of the general class of EGFR inhibitors.

\section{"Monoclonal antibody therapy may provide an important novel approach for patients with inoperable or metastatic colorectal cancer"}

Monoclonal antibody therapy may therefore provide an important novel approach for patients with inoperable or metastatic colorectal cancer. EGFR blockade may not however be the only receptor to target as Avastin (Genentech, Roche), an antivascular endothelial growth factor monoclonal antibody, has also recently been shown to have a significant overall survival benefit (when used in combination with Irinotecan) in a phase III randomised trial in chemo naïve patients with metastatic colorectal cancer. ${ }^{25}$ Other approaches to manipulate growth factor ligands and their receptors that are under active investigation include bispecific and single chain antigrowth factor receptor antibodies, immunotoxin conjugates, and antisense oligonucleotides. ${ }^{26}$

Numerous clinical studies on the use of growth factor inhibitors in the treatment of gastrointestinal cancers are underway. Of equal interest, but at a much earlier stage, is the idea that growth factor receptor blockers may also be useful in preventing or reducing the risk of progression of premalignant conditions, such as in Barrett's oesophagus and the adenoma-carcinoma sequence in colonic lesions.

\section{WHAT ARE THE RISKS OF GROWTH FACTOR AGONISTS?}

Advances in recombinant peptide technology now allow us to produce virtually pure peptide at moderate cost. This removes the concern of contamination with infectious agents (as seen in patients treated with growth hormone developing Creutzfeldt-Jakob disease) and the problems of development of antibodies to purified peptides obtained from other species (as seen with porcine insulin). There are however a number of areas of potential concerns, including the major worry that systemic use of potent growth factors may induce tumour progression in the gut area that is being treated (as for example when used for the treatment of colitis) or in distant organs (for example, lung tumours). As stated earlier, it is certainly true that several of these tumours appear to express functional growth factor receptors. A clinical correlate of this concern is that patients with acromegaly (increased systemic levels of the peptide "growth factor" growth hormone) have an increased risk of development of colonic carcinoma. $^{27}$

In this issue of Gut, Thulsen and colleagues ${ }^{28}$ report that one month's daily systemic treatment with GLP-2 (or its analogue Gly2-GLP-2) increased the size of colonic polyps in mice that had been pretreated with the carcinogen dimethylhydrazine [see page 1145]. A similar finding has been reported when systemic EGF was administered long term to "Min mice". ${ }^{29}$ Min mice are used as a model of the human defect seen in APC where the mouse homologue of the human APC gene has been deleted. In this model, for reasons that are poorly understood, the mouse phenotype tends to give predominantly small intestinal polyps, rather than colonic polyps. In both of these reports, size of tumour burden, rather than the number of tumours, was increased.

The use of animal models to determine the potential risk of peptide growth factor therapy in inducing cancer development in humans will always have its limitations and, to date, has provided somewhat contradictory results. In mice given the carcinogen dimethyhydrazine, an increased number of anal squamous cell carcinomas were seen if EGF was coadministered on alternate days for two weeks but no change in the number or size of colonic tumours was observed..$^{30}$ In contrast, an antagonistic relationship between EGF and azoxymethane on proliferation and tumour growth was reported following intracolonic administration of EGF. This suggests that while luminal EGF can increase normal colonic epithelial growth, it does not potentiate carcinogenesis. $^{31}$

\section{"The use of animal models to determine the potential risk of peptide growth factor therapy in inducing cancer development in humans will always have its limitations"}

In contrast with the results seen administering EGF and carcinogens to normal mice, a different series of conclusions have been reached when using genetically modified Min mice. These studies have suggested that normal EGFR activity is required for establishment of intestinal tumours as impaired EGFR signalling or pharmacological inhibition of EGFR resulted in a large reduction in polyp number, but not apparently of polyp progression. ${ }^{32}$ In addition, administration of the combination of a chemopreventative drug (sulindac) and an irreversible inhibitor of the EGFR dramatically reduced the tumour number in Min mice..33 Taken in the context of a need for caution, these results raise sufficient concerns that the risk/benefit for their use has to be carefully weighed and that any patient given such therapies will need regular subsequent supervision.

How can we reduce the risk? As for the use of non-steroidal anti-inflammatory drugs, administering the lowest possible dosage for the shortest time needed to achieve the required goal seems logical. In addition, the use of oral, as opposed to systemic, administration of growth factors provides one possible approach to limit regions exposed to these pharmacological levels of growth factors. However, for EGF and the trefoil peptides, the oral doses required to treat gastrointestinal damage may be up to a thousand times greater than when the peptide is given systemically, making oral therapy much more expensive. Stabilising growth factor peptide molecules against digestion in the small intestine is likely to be difficult due to the many different proteolytic enzymes produced by the pancreas. Possible strategies 


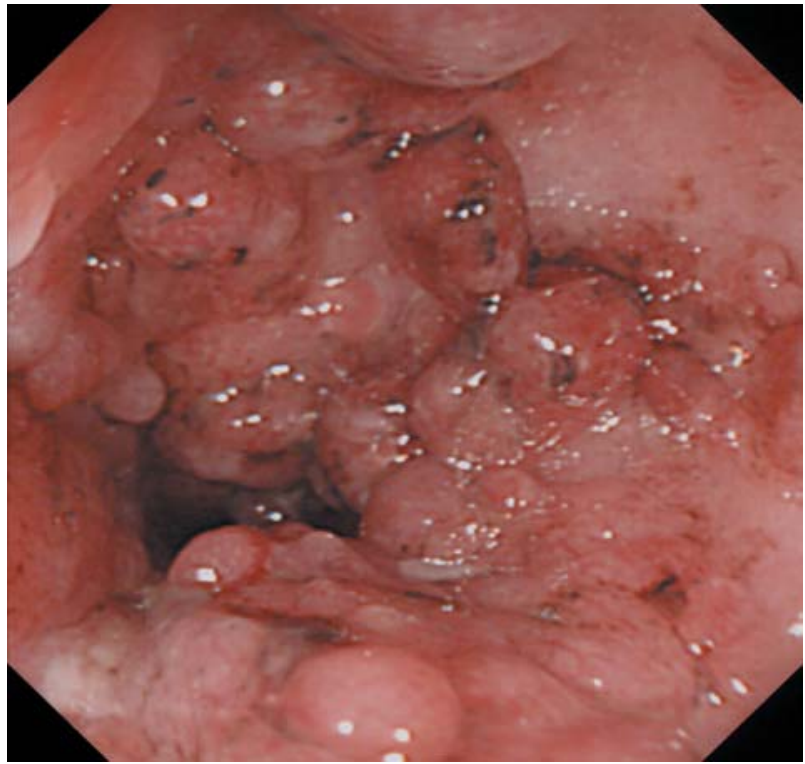

Figure 1 Potential value and concerns of growth factor agonists and antagonists. Endoscopic appearance of a colonic cancer in an area of pseudopolyposis resulting from longstanding ulcerative colitis. This patient did not receive growth factor or antagonist therapy. Growth factor agonists may be useful to treat several gastrointestinal disorders, such as inflammatory bowel disease. There is a concern however that this may subsequently increase the risk of malignant progression in the bowel or in distant sites if given systemically. In patients who develop gut malignancies, early studies suggest growth factor receptor blockade or tyrosine kinase inhibitors may prove clinically useful.

include administering the peptide in a site specific release formulation to overcome these problems.

\section{WHAT ARE THE RISKS OF GROWTH FACTOR ANTAGONISTS?}

As stated earlier, peptide growth factors have numerous effects. It is therefore possible that administration of these antagonists can have adverse effects on many different sites. Disruption or "knockout" models of various growth factors using transgenic models well demonstrate these concerns. Knockout of individual ligands, such as EGF or TGF- $\alpha$, causes minimal problems on phenotype although they may be associated with an increased susceptibility to injurious agents. ${ }^{34}{ }^{35}$ Patients taking non-steroidal anti-inflammatory drugs or similar drugs may therefore be at risk of increased side effects such as gastric ulceration. Based on animal models, the risks associated with complete receptor blockade are even higher. For example, knockout mice that have had the EGFR receptor completely inactivated have a lethal phenotype with problems in multiple organs, including gut and respiratory abnormalities. ${ }^{36}$

\section{SUMMARY}

The advent of recombinant peptide technology offers the potential to use one or several (to elicit synergistic responses) peptides to treat a variety of gastrointestinal conditions. It is important to note however that although cell culture and animal models have shown proof of concept, we are still at a relatively early stage in translating their use to standard clinical practice. Similarly, peptide and non-peptide antagonists of growth factor receptors show great potential as novel antichemotherapy agents.. However, their actual place in clinical practice is still at an early stage (fig 1 ) and vigilance is required to check for unexpected side effects at remote sites.

\section{Authors' affiliations}

R J Playford, H Wassan, S Ghosh, Gastroenterology Section, Division of Medicine, Imperial College London, Hammersmith Hospital, London, UK

\section{REFERENCES}

1 Perez-Soler R. HER 1/EGFR targeting: refining the strategy. Oncologist 2004:9:58-67.

2 Wells A. EGF receptor. Int J Biochem Cell Biol 1999;31:637-43.

3 Baselga J. New technologies in epidermal growth factor receptor-targeted cancer therapy. Signal 2000;1:12-21.

4 Berlanga J, Prats P, Remirez D. et al, Prophylactic use of epidermal growth factor reduces ischemia/reperfusion intestinal damage.Am J Pathol, 2002;161:373-9

5 Sullivan PB, Brueton MJ, Tabara Z, et al. Epidermal growth factor in necrotizing enterocolitis. Lancet 1991;338:53-4

6 Caballero ME, Berlanga J, Ramirez D, et al. Epidermal growth factor reduces multiorgan failure induced by thioacetamide. Gut 2001;48:34-40.

7 Playford RJ, Boulton R, Ghatei MA, et al. Comparison of the effects of TGF and EGF on gastrointestinal proliferation and hormone release. Digestion 1996:57:362-7.

8 O'Loughlin W, Winter M, Shun A, et al. Structural and functional adaptation following jejunal resection in rabbits: effect of epidermal growth factor. Gastroenterology 1994;107:87-93.

9 Drucker DJ. Biological actions and therapeutic potential of the glucagon-like peptides. Gastroenterology 2002;122:531-44.

10 Jeppesen PB, Hartman B, Thulesen J, et al. Elevated plasma glucagons-like peptide 1 and 2 concentrations in ileum resected short bowel patients with a preserved colon. Gut 2002;47:370-6.

11 Hirano M, Iweakiri R, Fujimoto K, et al. Epidermal growth factor enhances repair of rat intestinal mucosa damaged after oral administration of methotrexate. J Gastroenterol 1995;30:169-76.

12 Sonis ST, Lindquist L, Van Vugt A, et al. Prevention of chemotherapy-induced ulcerative mucositis by transforming growth factor beta 3. Cancer Res 1994:54:1135-8.

13 Howarth GS, Francis GL, Cool JC, et al. Milk growth factors enriched from cheese whey ameliorate intestinal damage by methotrexate when administered orally to rats. J Nutr 1996;126:2519-30

14 Gordler NM, McGurk M, Aqual S, et al. The effect of EGF mouthwash on cytotoxic-induced oral ulceration. Am J Clin Oncol 1995;18:403-6.

15 Procaccino F, Reinshagen M, Hoffman P, et al. Protective effect of epidermal growth factor in an experimental model of colitis. Gastroenterology 1994; 107:12-17.

16 Sinha A, Nightingale JM, West KP, et al. Epidermal growth factor (EGF) enemas treat ulcerative colitis. New Engl J Med 2003:349:350-7.

17 Khan Z, Macdonald C, Wicks AC, et al. Use of the 'nutriceutical', bovine colostrum, for the treatment of distal colitis. Aliment Pharmacol Ther 2002; 16:1917-22.

18 Sandborn WJ, Sands BE, Wolf DC, et al. Repifermin (keratinocyte growth factor-2) for the treatment of active ulcerative colitis: a randomized, doubleblind, placebo-controlled, dose-escalation trial. Aliment Pharmacol Ther 2003;17:1355-64

19 Verschraegen CF, Westphalen S, Hu W, et al. Phase II study of cetrorelix, a luteinizing hormone-releasing hormone antagonist in patients with platinumresistant ovarian cancer. Gynecol Oncol 2003;90:552-9.

20 Emons G, Grundker C, Gunthert AR, et al. GnRH antagonists in the treatment of gynaecological and breast cancers. Endocr Relat Cancer 2003;10:291-9.

21 Salomon DS, Brandt R, Ciardiello F, et al. Epidermal-growth factor related peptides and their receptors in human malignancies. Crit Rev Oncol/ Haematol 1995; 19:183-232.

22 Woodburn JR. The epidermal growth factor receptor and its inhibition in cancer therapy. Pharmacol Ther 1999:82:241-50.

23 Ciardiello F, Caputo R, Bianco R, et al. Antitumour effect and potentiation of cytotoxic drugs activity in human cancer cells by ZD1839 ('Iressa') an epidermal growth factor receptor-selective tyrosine kinase inhibitor. Clin Cancer Res 2000;6:2053-63.

24 Saltz LB, Meropol NJ, Loehrer PJ, et al. Phase II trial of Cetuximab in patients with refractory colorectal cancer that expresses the epidermal growth factor receptor. J Clin Oncol 2004;22:1177-9.

25 Fernando NH, Hurwitz HI. Inhibition of vascular endothelial growth factor in the treatment of colorectal cancer. Semin Oncol 2003;30:39-50.

26 Noonberg SB, Benz CC. Tyrosine kinase inhibitors targeted to the epidermal growth factor receptor subfamily: role as anticancer agents. Drugs 2000;59:753-67.

27 Jenkins PJ, Fairclough PD, Richards T, et al. Acromegaly, colonic polyps and carcinoma. Clin Endocrinol (Oxf) 1997;47:17-22.

28 Thulsen J, Hartmann B, Hare KJ, et al. Glucagon-like peptide 2 (GLP-2) accelerates the growth of colonic neoplasms in mice. Gut 2004:53:1145-50.

29 Bashir O, Fitzgerald AJ, Berlanga-Acosta J, et al. Effect of EGF administration on intestinal cell proliferation, crypt fission and polyp formation in Min mice. Clin Sci 2003;105:323-30.

30 Kingsnorth AN, Abu-Khalaf M, Ross JS, et al. Potentiation of 1, 2dimethylhydrazine-induced anal carcinoma by epidermal growth factor in mice. Surgery 1985;97:696-700.

31 Reeves JR, Richards RC, Cooke T. The effects of intracolonic EGF on mucosal growth and experimental carcinogenesis. Br J Cancer 1991;63:223-6.

32 Roberts RB, Min L, Washington MK, et al. Importance of epidermal growth factor receptor signaling in establishment of adenomas and maintenance of carcinomas during intestinal tumorigenesis. Proc Natl Acad Sci U S A 2002;99:1521-6 
33 Torrance $\mathrm{CJ}$, Jackson PE, Montgomery $\mathrm{E}$, et al Combinatorial chemoprevention of intestinal neoplasia. Nat Med 2000;6:1024-8.

34 Abbott BD, Buckalew AR, DeVito MJ, et al. EGF and TGF-alpha expression influence the developmental toxicity of TCDD: dose response and AhR phenotype in EGF, TGF-alpha, and EGF+TGF-alpha knockout mice. Toxicol Sci 2003;71:84-95.
35 Troyer KL, Luetteke NC, Saxon ML, et al. Growth retardation, duodenal lesions, and aberrant ileum architecture in triple null mice lacking EGF, amphiregulin, and TGF-alpha. Gastroenterology 2001;121:68-78.

36 Miettinen PJ, Berger JE, Meneses J, et al. Epithelial immaturity and multiorgan failure in mice lacking epidermal growth factor receptor. Nature 1995;376:337-41.

\section{EDITOR'S QUIZ: GI SNAPSHOT}

\section{A calcified caecal mass}

Robin Spiller, Editor

\section{Clinical presentation}

A 64 year old woman with a history of Bentall operation and maintenance haemodialysis due to multiple myeloma presented with a positive faecal occult blood test. She denied abdominal symptoms. Physical examination was unremarkable. Leucocytosis was absent. Colonoscopy showed a globular submucosal tumour with the appendiceal orifice (arrow) on its top (fig 1). Computed tomography demonstrated a cystic lesion with "eggshell"-like mural calcification (arrow) in the expected region of the appendix (fig 2).

\section{Question}

What is the diagnosis?

See page 1081 for answer

This case is submitted by:

A Hokama, T Makishi, R Tomiyama, F Kinjo, A Saito, First Department of Internal Medicine, University of the Ryukyus, Okinawa, Japan S Yamashiro, I Kinjo, K Miyagi, Y Kuniyoshi, K Koja, Second Department of Surgery, University of the Ryukyus, Okinawa, Japan

Correspondence to: Dr A Hokama, First Department of Internal Medicine, University of the Ryukyus, 207 Uehara, Nishihara, Okinawa 903-0215, Japan; hokama-a@med.u-ryukyu.ac.jp

doi: $10.1136 /$ gut.2003.034009
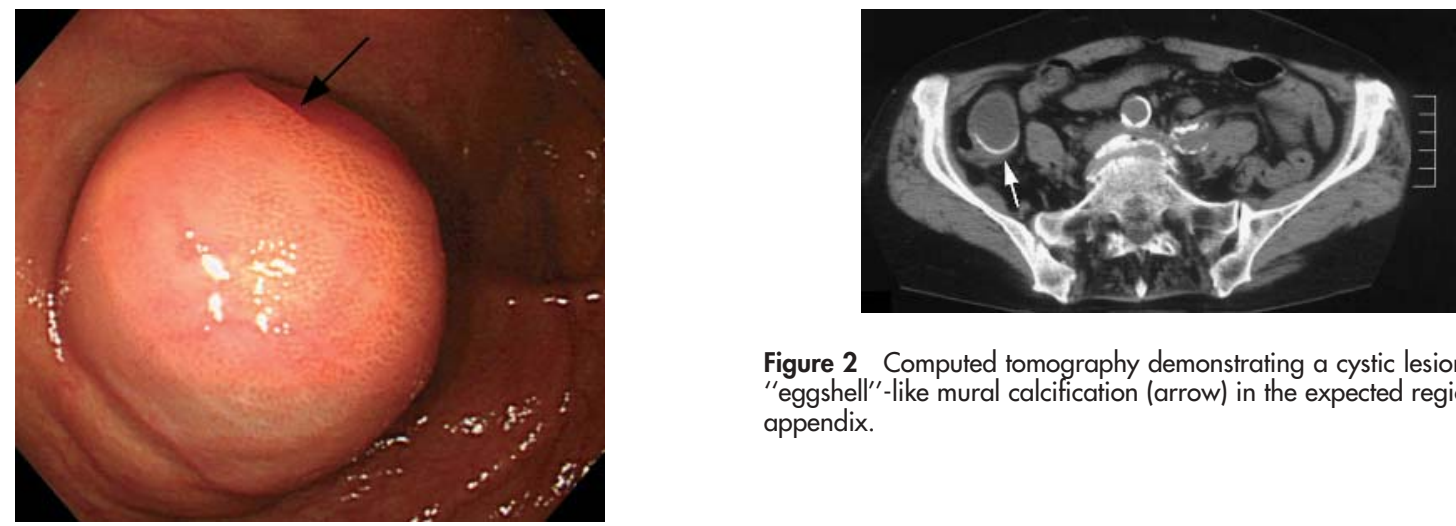

Figure 2 Computed tomography demonstrating a cystic lesion with "eggshell"-like mural calcification (arrow) in the expected region of the appendix.

Figure 1 Colonoscopy showing a globular submucosal tumour with the appendiceal orifice (arrow) on its top. 